\title{
Bioactive compounds in some principal mushrooms: An association to adverse effects
}

\author{
Natalia González-Quero ${ }^{1,2}$ and Pilar Martínez ${ }^{1, *}$ \\ ${ }^{1}$ National Institute of Toxicology and Forensic Science (INTCF), Biology Service, José Echegaray 4, 28232 Las Rozas de \\ Madrid, Spain. \\ ${ }^{2}$ Natalia González Quero, Medical Department, GSK, PTM Severo Ochoa 2, 28760 Madrid, Spain.
}

Publication history: Received on 08 November 2020; revised on 15 November 2020; accepted on 16 November 2020

Article DOI: https://doi.org/10.30574/gscarr.2020.5.2.0103

\begin{abstract}
Mushrooms are widely used in Asian medicine, both as dietary supplements and as nutraceutical foods. Some principal fungi have recently become popular in Europe for their nutritional and health benefits, and a large number of bioactive compounds have been isolated in several taxa showing antioxidant, anti-inflammatory, antiviral, antitumor activities and other biological properties with great therapeutic application. Separate research has been done separately for the different species. The aim of the present review was to give an overview of the present knowledge regarding bioactive compounds in ten of the most common species, their options in therapeutic use and, for the first time, their possible toxicity or adverse effects. Boletus edulis, Ganoderma lucidum, Grifola frondosa, Hericium erinaceus, Hypsizygus marmoreus, Lentinula edodes, Morchella esculenta, Pleurotus ostreatus, Poria cocos and Trametes versicol have great potential as functional foods and as a source of drugs for pharmaceutical science and medicine. Some adverse effects, however, were found to occur in individual daily consumption and during clinical trials. More research is needed to make a good rational use of these medicinal compounds.
\end{abstract}

Keywords: Mushrooms Bioactive Compounds; Adverse Effects; Antioxidant; Anti-Inflammatory; Antiviral; Antitumor

\section{Introduction}

Mushrooms, a large group of the higher Fungi, are widely distributed throughout the biosphere. The number of mushroom species on the Earth is estimated to be 140,000 and only 10\% are known. Even among the known species the proportion of well investigated mushrooms is very low [1]. In recent years, mushroom production has increased at a faster rate than almost any other agricultural product, in part due to their medical characteristics. They have outstanding nutritional value so they are considered as functional food, which means that they are beneficial to the body not only in terms of nutrition, but also for improved health [2-4]. Medicinal mushrooms and their extracts have a large number of bioactive compounds, called secondary metabolites. Such include polysaccharides, beta-glucans, triterpens, sterols, glycoproteins and immunomodulating compounds, among others, which have great therapeutic applications in human health as they possess many properties [2]. Tumor diseases are one of the main causes of death worldwide. The experience from Asian and Eastern European countries shows that mushrooms can play an important role, for example, in prevention and treatment of cancer [1]. Thus, micotherapy is one of the most promising integrative approaches in cancer therapy [5]. Currently, several medicinal extracts have widespread use in Japan, Korea and China, as potential adjuvants to radiation treatments and chemotherapy [6-10]. In cancer therapy, a variety of adverse effects are associated with the treatments used in conventional medicine, so that cancer patients are likely to request complementary and alternative medicine.

\footnotetext{
* Corresponding author: Pilar Martínez; Tel.+34917688926. email: pilarm.fernandez@justicia.es

National Institute of Toxicology and Forensic Science (INTCF), Biology Service, José Echegaray 4, 28232 Las Rozas de Madrid, Spain. 
Natural antioxidants can be effective to help the human body in reducing oxidative damage by the reactive oxygen species, ROS molecules, derived from the metabolism of oxygen [11]. Moreover, in recent years, the antioxidant, antiinflammatory and antiviral properties, among others, of numerous plants, lichens and mushrooms have been widely reported [2,12]. Due to this fact, proper and more abundant investigations are necessary to lead us to use these species as alternative medicines in the future. In order to make use of the biological compounds, their identification and the study of their mechanisms of actions are necessary prior application. However, some fungi may be suspected to cause adverse effects. The present study intends to review the functionality of the main biological compounds and their registered possible toxicity or adverse effects according to some principal mushrooms which are well known as food or because of their medicinal properties. The following ten species were selected for study due to their most predominant medical properties: Boletus edulis, Ganoderma lucidum, Grifola frondosa, Hericium erinaceus, Hypsizygus marmoreus, Lentinula edodes, Morchella esculenta, Pleurotus ostreatus, Poria cocos and Trametes versicolor.

\section{Material and methods}

The present review will focus on the identification of the mushrooms bioactive compounds, therapeutic use, clinical trials and their possible toxicity or adverse effects. Eligible studies, published between 1974 and 2020, were identified by conducting searches of electronic database. The following search terms were used: medicinal mushroom, bioactive compounds, case report, trials, mycotherapy, toxicity, adverse effect, B. edulis, G. lucidum, G. frondosa, H. erinaceus, H. marmoreus, L. edodes, M. esculenta, P. ostreatus, P.cocos and T. versicolor. Some examples of methodology are described in this section.

In order to identify and quantify their content in the mycelia or fruiting bodies of the mushrooms, different techniques have been used. For example, the ergothioneine content in Lentinula edodes, Pleurotus ostreatus, and Grifola frondosa was analysed by high-performance liquid chromatography (HPLC) and liquid chromatography-mass spectroscopy (LCMS) [13]. Boledulins A-C, isolated from the cultures of the basidiomycete Boletus edulis, were established by means of spectroscopic methods [14]. Lectin was isolated from B. edulis by affinity chromatography on a chitin column [15]. In particular, Ren et al. $[16,17]$ described the extraction, isolation, purification, structural analysis and determination of the molecular weight of lentinan from L. edodes, while a crystallographic assay was used to identify the beta-glucans from $G$. frondosa and G. lucidum [5]. The technique to isolate the bioactive compounds of hericenones and erinacines, founded in H. erinaceus, was the extraction with ethanol, acetone or water, followed by fractionation and purification by several chromatographies [15].

A more complex process was the extraction of the heteropolysaccharide FMP-1 from the fruiting bodies of Morchella esculenta. Its polysaccharide was separated and purified by column and gel permeation chromatographies and finally analysed by gas chromatography [18]. Recently, the UHPLC-QTOF-MS/MS method has been used for the simultaneous determination of eight triterpene compounds from Poria cocos extract in rat plasma [19]. The identification of a biological active fraction in the filtrate of a medicinal mushroom, like Trametes versicolor, following the partial chemical characterization of the polysaccharide therein contained (henceforth referred as tramesan) was described by Scarpari et al. [20], as an example of extraction of a bioactive compound. The mycelia were separated from the culture filtrates by subsequent filtrations and the mycelia-purified culture filtrate was lyophilized and utilized for subsequent analyses. Suspensions of the lyophilized T. versicolor culture filtrate (for example $1 \mathrm{~g}$ in $30 \mathrm{~mL} \mathrm{of} \mathrm{H}_{2} \mathrm{O}$ ) were filtered to separate the insoluble from the soluble part. The remaining solution was cooled and precipitated with cold etanol, followed by centrifugation and dissolution in phosphate buffer. Finally, the polysaccharide fractions were separated by lowpressure size exclusion chromatography and their molecular mass was evaluated by high performance size exclusion chromatography (HP-SEC) [20].

After reviewing the literature search for clinical trials, this manuscript provides solid evidence that some of the bioactive compounds, found in seven of the ten species, are in clinical use, primarily in Asian countries. Different methods have been used to conduct the trials: randomised or non-randomised, double-blind, placebo-controlled, observational, openlabel, multicentre studies, among others, some of which are mentioned in the following section. We finally tried to address the possible existence of some adverse effects.

\section{Results and discussion}

The awareness of mushrooms as an important source of biologically active substances, with medicinal potentials, has only recently emerged where, however, only few associated adverse effects and/or toxicities were found. Table 1 shows: i) The different bioactive compounds that have been isolated from the selected fungi species, which demonstrated 
effective properties to improve health; and ii) A relation to the toxicity effects. Main properties of the different active compounds hereby explained were: the antioxidant, anti-inflammatory, antiviral and antitumor activities.

Table 1 Bioactive compounds, some effective properties to improve health and possible adverse effects related to the species B. edulis, G. lucidum, G. frondosa, H. erinaceus, H. marmoreus, L. edodes, M. esculenta, P. ostreatus, P.cocos and T. versicolor.

\begin{tabular}{|c|c|c|c|}
\hline Species & Bioactive Compounds & $\begin{array}{l}\text { Therapeutic } \\
\text { use/bioactivities }\end{array}$ & Adverse effects \\
\hline Boletus edulis & $\begin{array}{l}\text { Boledulins } \\
\text { Ergothioneine } \\
\text { Indole constituents } \\
\text { Lectins } \\
\text { Lovastatin }\end{array}$ & $\begin{array}{l}\text { Antioxidant } \\
\text { Antitumoral }\end{array}$ & Food allergy \\
\hline Ganoderma lucidum & $\begin{array}{l}\text { Adenosine } \\
\text { Beta-D-Glucan } \\
\text { Ergosterol } \\
\text { Ergosterol peroxide } \\
\text { Ganopoly } \\
\text { Ganoderic acids } \\
\text { Ganodermanondiol } \\
\text { Ganoderol } \\
\text { Heterogalactan-protein } \\
\text { complex } \\
\text { Lucidimins A-D } \\
\text { Lucidimine E } \\
\text { MD-fraction } \\
\text { Protein of LZ-8 } \\
\text { Triterpenoids }\end{array}$ & $\begin{array}{l}\text { Angiotensin converting } \\
\text { enzyme-inhibitory } \\
\text { Antiacetylcholinesterase } \\
\text { Anti-aging } \\
\text { Anticancer } \\
\text { Antidiabetic or hypoglycemic } \\
\text { Anti-HIV } \\
\text { Anti-inflammatory } \\
\text { Antiallergic } \\
\text { Antimicrobial } \\
\text { Antioxidant } \\
\text { Antitumor } \\
\text { Colesterol synthesis inhibitor } \\
\text { Hypotensive } \\
\text { Immunomodulator } \\
\text { Improves T-lymphocites } \\
\text { response to cytokines } \\
\text { Inhibitory platelet aggregation } \\
\text { Regulates body testosterone } \\
\text { Stimulates macrophages } \\
\text { activity }\end{array}$ & Hepatitis \\
\hline Grifola frondosa & $\begin{array}{l}\text { Cyanhydric acid } \\
\text { D fraction } \\
\text { Ergosterol } \\
\text { Ergothioneine } \\
\text { Grifolan } \\
\text { Heteropolysaccharide } \\
\text { Lectins } \\
\text { Linoleic acid } \\
\text { Oleic acid }\end{array}$ & $\begin{array}{l}\text { Anticancer } \\
\text { Antidiabetic type } 2 \\
\text { Anti- } \alpha \text {-glucosidase activity } \\
\text { Antihyperglicemic } \\
\text { Antihyperlipidemic } \\
\text { Antihypertensive } \\
\text { Anti-inflammatory } \\
\text { Antitumor } \\
\text { Antiviral } \\
\text { Immunomodulator }\end{array}$ & $\begin{array}{l}\text { Acute encephalopathy } \\
\text { Occupational } \\
\text { hypersensitivity } \\
\text { pneumonitis } \\
\text { Respiratory irritation } \\
\text { caused by grifolan } \\
\text { aerosols }\end{array}$ \\
\hline
\end{tabular}


GSC Advanced Research and Reviews, 2020, 05 (02), 031-047

\begin{tabular}{|c|c|c|c|}
\hline Hericium erinaceus & $\begin{array}{l}\text { DLPE* } \\
\text { Ergothioneine } \\
\text { Erinacine A } \\
\text { Erinacine B } \\
\text { Hericenones } \\
\text { Lectins } \\
\text { Monochlorobenzenes } \\
\text { compounds } \\
\text { 4-pyranones } \\
\text { Statins }\end{array}$ & $\begin{array}{l}\text { Activity against ER stress- } \\
\text { dependent } \\
\text { Antidepressant } \\
\text { Anti-HIV } \\
\text { Anti-H. pylori activity } \\
\text { Antimicrobial } \\
\text { Antitumorgenic } \\
\text { Hemagglutinating activity } \\
\text { Hypoglycemic effects } \\
\text { Hypolipidemic effects } \\
\text { Indigestion, gastric ulcer } \\
\text { Neurasthenic, synthesis of } \\
\text { nerve growth factor } \\
\text { Neurohealth properties }\end{array}$ & \\
\hline Hypsizygus marmoreus & $\begin{array}{l}\text { Ergothioneine } \\
\text { Hypsin } \\
\text { Hypsiziprenol A9 } \\
\text { Lovastatin } \\
\text { MSPS* } \\
\text { Sterols }\end{array}$ & $\begin{array}{l}\text { Anti - epstein-barr } \\
\text { Anti-inflammatory } \\
\text { Antiproliferative } \\
\text { Antitubercular }\end{array}$ & \\
\hline Lentinula edodes & $\begin{array}{l}\text { Adenine derivates } \\
\text { Agaritine } \\
\text { Ergothioneine } \\
\text { Eritadenine } \\
\text { Formaldehyde } \\
\text { Galactose } \\
\text { Glucose } \\
\text { Lectins } \\
\text { Lentinamyicin } \\
\text { Lentinan } \\
\text { Mannose } \\
\text { Polyisoprenoid alcohols } \\
\text { RNA from spores } \\
\text { Statins }\end{array}$ & $\begin{array}{l}\text { Antibacterial } \\
\text { Antifungal } \\
\text { Antihypercholesterolemic } \\
\text { Anti-inflammatory } \\
\text { Antilipidemic Antioxidant } \\
\text { Antioxidant enzyme activity } \\
\text { Antitumor } \\
\text { Antiviral (influenza infections) } \\
\text { Arterosclerosis } \\
\text { Headache } \\
\text { Hepatocirrhosis } \\
\text { Immunopotentiator } \\
\text { Vertigo }\end{array}$ & $\begin{array}{l}\text { Allergy } \\
\text { Eosinophilia } \\
\text { Flagellate dermatitis } \\
\text { Gout } \\
\text { Low blood pressure }\end{array}$ \\
\hline
\end{tabular}

\subsection{Antioxidant activity}

The highly reactive oxygen species (ROS) molecules can cause extensive damage to cells and tissues, with various degenerative disorders, such as cardiovascular disease, aging, and neurodegenerative diseases, like Alzheimer's disease, mutations and cancer [11]. Considering the different species, Boletus edulis, one of the most popular mushroom species due to its exceptional flavour and high nutritional value, was found to have high antioxidant properties [21]. Antioxidants of $B$. edulis were polyphenols, flavonoids, $\beta$-carotene and lycopene, as well as vitamin C [21, 22]. Most antioxidants are sensitive to heat treatment, so when $B$. edulis was prepared for consumption it showed a lower antioxidant activity than when fresh. However, antioxidant compounds could be taken as medicine, for example, as ergothioneine, and B. edulis and some Pleurotus sp. proved to have high amounts [23].

Ganoderma lucidum peptide (GLP) has been reported as the major antioxidant component of G. lucidum and this property makes it a candidate for anti-aging [24]. Terpenes are together with the polysaccharides, like ganopoly, the 
bioactive compounds that make reishi (G. lucidum) one of the most antioxidant natural substances that exist. The antioxidative and free radical scavenging effects of the polysaccharides and triterpenoids from G. lucidum were shown in different oxidative injury models [25].

The popular mushroom Lentinula edodes, also known as shiitake, is highly consumed as health food in China, Japan, and other Asian countries. Among its bioactive components, the polysaccharide lentinan is the most extensively investigated due to its abundant nutraceutical and pharmaceutical potentials $[16,17]$. Currently, lentinan has attracted considerable attention due to its antioxidant activities [26, 27]. Similarly, the enzymatic residue polysaccharide (ERPS) of the species has antioxidant, anti-inflammatory and protective activities against lipopolysaccharide (LPS)-induced sepsis, demonstrating that it can be applied as natural and functional food for the prevention and alleviation of sepsis-induced multiple organ damage [17].

The beta-glucan isolated from Pleurotus ostreatus, known as pleuran, proved to have an effect on the antioxidant status of the organism in rats [28]. A diet containing either $10 \%$ pleuran or $10 \%$ cellulose was compared with a cellulose-free diet. The antioxidant effect of orally administered pleuran was documented by significantly lower levels of the primary products of lipoperoxidation and conjugated dienes in the colon, liver, and erythrocytes [28]. Particularly significant was the reduction of conjugated dienes in the colon following this compound administration. In this way, pleuran added to the diet has reduced lipoperoxidation and increased the activity of antioxidant enzymes. Another attractive natural antioxidant is the FMP-1 found in Morchella esculenta, which has been prepared from methanolic extracts of the mycelia, showing a high antioxidant activity (85.4\% at $25 \mathrm{mg} / \mathrm{ml}$ ) [29]. Oxidative stress is considered to involve cell death in severe pulmonary diseases like in the idiopathic pulmonary fibrosis (IPF). In this way, the findings in Li et al. [29] suggested that the FMP-1 attenuated the cellular oxidative stress through the PI3K/AKT pathway and therefore it could be explored as a natural potential antioxidant to lower oxidative stress relevant to the progression of IPF.

\subsection{Anti-inflammatory activity}

Inflammation is a natural response of the immune system to damaging factors, e.g. physical, chemical and pathogenic. Deficiencies of antioxidants, vitamins, and microelements, as well as physiological processes, such as aging, can affect the body's ability to resolve inflammation [30]. Some mushrooms are rich in anti-inflammatory components, such as polysaccharides, phenolic and indolic compounds, mycosteroids, fatty acids, carotenoids, vitamins and biometals. Consulted literature for this review indicated that some of the fungi species selected to study exhibited favorable therapeutic and health-promoting benefits, particularly in relation to diseases associated with inflammation.

Ganoderma lucidum, as tea, dietary supplement, and medicine, is widely used in Asian countries [31, 32]. In order to discover its anti-inflammatory constituents and to provide some references for its usage, their fruiting bodies have been studied leading to the isolation of six new triterpenoids [32] and five new aromatic compounds, designed as lucidumins A-D and lucidimine E [31]. The bioactive evaluation showed significant anti-inflammatory activities against LPSinduced nitric oxide (NO) production in RAW264.7 macrophages, a murine macrophage cell line. This medicinal mushroom has a large number and variety of terpenes among which are the ganoderic acids, lucidenic acid and ganoderol (Table 1). In conclusion, terpenes from G. lucidum inhibit the release of pro-inflammatory substances [31].

Another anti-inflammatory mushroom is Grifola frondosa, which was proved to contain three compounds: ergosterol, ergostra-4,6,8,22-tetraen-3-ona and 1-oleo-2-linoleil-3-palmitoilglicerol. These compounds showed the cyclooxygenase (COX) enzyme inhibitory activity which was reported for the first time in Zhang et al. [33]. COX is an enzyme which is responsible for formation of prostanoids, including thromboxane and prostaglandins such as prostacyclin, from arachidonic acid. It is widely used to determine the anti-inflammatory effects of potential therapeutic products. The COX isozymes involved in prostaglandin synthesis are COX-1 and COX-2. It is reported that selective COX2 inhibitors are mainly responsible for anti-inflammatory activities.

The synergistical action of inflammation response with oxidative stress has also been reported to be a response to the pathogenesis LPS-induced lung damage. A study showed that mycelia selenium polysaccharides (MSPS) from Hypsizygus marmoreus might be a potencially effective candidate medicine for the treatment of lung pathogenesis and its complications [34].

There are fewer recent studies on Lentinula edodes [16, 17], Morchella esculenta [35] and Poria Cocos [36], showing the three species anti-inflammatory capacities. 


\subsection{Antiviral properties}

New viruses emerge all the time and presently we have a limited number of vaccines and only a few antivirals to combat viral diseases. These diseases cannot be treated by common antibiotics so specific drugs are urgently needed. Some compounds isolated from mushrooms with antiviral effects have been described. In the present review, several triterpenes from Ganoderma lucidum: ganoderiol F, ganodermanontriol and ganoderic acid, as well as adenosine and other polysaccharides were found to be active as anti-HIV-1 (human immunodeficiency virus type 1) agents [37, 38].

The D-fraction from Grifola frondosa was tested in a long-term trial on patients with HIV. A total of $85 \%$ of responders reported an increased sense of well-being with regard to various symptoms and secondary diseases caused by HIV [39]. Furthermore, a novel heteropolysaccharide, namely GFP1 from G. frondosa was extracted and the study demonstrated that it has antiviral activity which could be valuable as a potentially new anti-enterovirus 71 (EV71) therapeutic compound [40].

Seven sterols and three hypsiziprenols were isolated from the non-saponifiable lipid (NSL) fraction of the extract of Hypsizygus marmoreus [1]. Among them, ergosterol exhibited a moderate inhibitory effect against Epstein-Barr virus early antigen (EBV-EA) activation, induced by a tumor promoter, called 12-0-tetradecanoylphorbol-13-acetate (TPA) in Raji cells. That still might be of importance as a chemopreventive compound from the species, providing its most predominant lipid constituent, which demonstrated to inhibit the promotion of skin papilomas caused by TPA. The hypsin from $H$. marmoreus, a novel thermostable ribosome-inactivating protein, also proved antifungal and antiproliferative activities [41].

A novel lentinan (LNT-1) was recently extracted from Lentinula edodes mycelia with antiviral mechanisms mainly involved in the direct inactivation and inhibition of the viral replication [17]. The results indicated that the inhibitory effects of LNT-I on infectious hematopoietic necrosis virus (IHNV) infection were possibly attributed to the regulation of the innate immune responses and specific immunity [17]. The extract named LEM from the culture medium of $L$. edodes mycelia was also reported to have a role in the inhibition of the infectivity and cytopathic effect of the HIV-1 due to the immunoactive fractions obtained from the extract [42]. Considering the antiviral effect of lentinan, Sarkar et al. [43] showed that the compound had immune-stimulatory impacts by blocking the release of herpes-simplex virus type1 from tissue culture cells. Similarly, the protein-bound polysaccharides PSK (Polysaccharide-K, commercial Krestin) and PSP (polysaccharopeptide) from Trametes versicolor were found to have an in vitro antiviral effect on HIV and the cytomegalovirus [44].

\subsection{Antitumor activity}

A novel lectin named BEL (Boletus edulis lectin) was isolated from the fruiting bodies of B. edulis, which selectively inhibits the proliferation of several malignant cell lines and binds the neoplastic cell-specific T-antigen disaccharide, Galß1-3GalNAc [15]. Similarly, recent findings indicated that some isolated polysaccharides from Ganoderma $\mathrm{sp}$. increase anti-tumour immune responses by motivating the activity of natural killer cells and cytotoxic T-lymphocytes $[45,46]$. The agent polysaccharide from $G$. lucidum, ganopoly, for example, has reported an antitumor activity with a broad spectrum of immuno-modulating activities, and therefore may represent a novel promising immunotherapeutic agent in cancer treatment [47]. Further studies about the compounds are needed to explore the optimum dosing, efficacy and safety, alone or in combination, with radiotherapy and chemotherapy [6,7]. The triterpenoid ganodermanondiol, isolated from the species, was also shown to effectively regulate melanogenesis in B16F10 melanoma cells [48].

Recently, Liu et al. [18] investigated the chemical structure and the anti-proliferating and antitumor activities of the polysaccharide MEP extracted from Morchella esculenta. Apoptosis tests proved that MEP could inhibit the proliferation and growth of human colon cancer HT-29 cells in a time- and dose-dependent manner within $48 \mathrm{~h}$. Similarly, in recent years, cytostatic activities against tumor cells were shown in vitro for other mushroom components of Pleurotus ostreatus, with interesting antimutagenic effects found after investigation on methanolic extracts of the species [1], on Grifola frondosa and on Poria cocos and its constituents [49]. In the latter, especially the triterpenoids, such as pachymic acid, and polysaccharides, such as $\beta$-glucan, have been found to exhibit a broad spectrum of antitumor activities both in vitro and in vivo, demonstrating the potential use of these species, as a functional food and natural source of novel leading compounds for herbal medicine management. In terms of the molecular mechanism, these isolated compounds exert cytotoxicity against human lung cancer cells by inducing apoptosis accompanied by, for example, mitochondrial perturbation. These findings provide experimental evidence and a molecular explanation for the anticancer properties, especially against lung cancer, and support the previous notion that $P$. cocos species could successfully be applied for cancer treatment $[50,51]$. 


\subsection{Immunomodulators and adjuvant tumor therapy}

The so called 'immunomodulators' (biological response modifier, immunopotentiators and immunostimulants) are probably one of the most important botanic medicinal drugs used in Asian countries today [1]. Due to the toxicity and side effects of the chemotherapeutic drugs, more and more cancer patients have turned to herbal medicine for complementary treatment. The MD-fraction from $G$. frondosa, the lentinan agent from L. edodes and PSK and PSP from T. versicolor are in clinical use for adjuvant tumor therapy (immunotherapy), in addition to the major cancer therapies like chemotherapy, radiotherapy and surgical operation [1,52] and in HIV patients [53]. Thus, the MD-fraction is known to reduce tumor cell viability and was found to be the most potent compound, enhancing the immune system, via oral administration or injection, leading to the highest reduction of the rate of cancer proliferation. A combination of immunotherapy with MD-fraction and chemotherapy suggested that the bioactive compound might decrease the size of lung, liver, and breast tumors [54]. Secondly, the administration of lentinan, in addition to chemotherapy, led to the prolongation of survival time, restoration of immunological parameters and improvement of life quality in individuals with stomach cancer, colon cancer, and other carcinomas, in comparison to patients who had chemotherapy alone [1]. Clinical studies to this respect have been done especially in Asian countries [8-10]. Considering the bioactive compounds from T. versicolor, the efficacy of the adjuvant immunotherapy with PSK has also been demonstrated in human clinical trials. For example, resected colorectal cancer patients were treated orally with PSK and the increased disease-free survival curve of the PSK group, over the control group, was statistically significant [55]. Another controlled clinical trial of PSP was conducted in 485 cancer patients where the administration of PSP had raised one year the survival rate of patients [56].

The species Pleurotus ostreatus has been used as an immunomodulator in the treatment of ulcerative colitis. When pleuran was locally administered, with or without concomitant parenteral pretreatment, the colonic damage was effectively reduced [57]. The results on the protective effect of orally applied pleuran in the prevention or dietetic therapy of inflammatory colon diseases are promising. Pleuran has also been proved to be effective in the treatment of the recurrent respiratory tract infections (RRTIs), which are a very important problem in pediatric praxis. The active treatment with pleuran resulted in a significant reduction of peripheral blood eosinophilia and stabilized the levels of total IgE in serum. Thus, pleuran showed a potential anti-allergic effect. This recently-known effect could expand the application of this natural immunomodulator also as a complementary adjuvant therapy in allergic patients [58].

\subsection{Other biological activities}

Apart from the main beneficial effects more frequently described by the authors, the species have shown other diverse medicinal properties, as we hereby indicate for each species.

\subsubsection{Ganoderma lucidum}

Scientific evidence recently revealed that G. lucidum modulates the composition of gastrointestinal microbiota in different disorders, such as obesity and hypercholesterolemia [5]. The species also has potential for neurological disease treatment, which has proven promising for the progression of Alzheimer's diseases [46]. In addition, ganodermanondiol, isolated from G. lucidum, exerts an inhibitory effect on tyrosinase as well as other isolated compounds which have antiacetylcholinesterase, antimicrobial, antidiabetic and anti-angiogenic effects [46].

\subsubsection{Grifola frondosa}

Regular consumption of $G$. frondosa is believed to improve spleen, stomach, and nerve functions and to cure skin diseases. Results demonstrated that organic extracts and polysaccharides of $G$. frondosa fruiting bodies possessed a different magnitude of potency in inhibiting $\alpha$-amylase and $\alpha$-glucosidase activities [59]. The polysaccharide GFP also relieved insulin resistance of HepG2 cells by the Akt-GSK-3 pathway, thus showing an antidiabetic type 2 activity. Western-blotting results showed that the HepG2 cell model treated with GFP activated the insulin receptor protein (IRS) in the cell membrane and increased phosphorylated-AktSer473 expression, which had an inhibition of glycogen synthase kinase (GSK-3). The downregulation of GSK-3 stimulated synthesis of intracellular glycogen. More recent results supported that the GFP increased the metabolism of glucose and stimulated synthesis of intracellular glycogen through the Akt/GSK-3 pathway [60]. Furthermore, this polysaccharide which is a beta-glucan, stimulates the hematopoietic progenitor cell differentiation, the granulocyte colony-stimulating factor production, and the recovery of peripheral blood leukocytes after bone marrow injury. A phase II trial examined the effects of maitake on innate immune function in myelodysplastic syndromes (MDS) which are characterized by ineffective erythropoiesis with dysplastic bone marrow leading to peripheral cytopenia, risk of infection, and progression to acute myelogenous leukemia. Thus, the results showed that maitake beta-glucan consumption improves neutrophil and monocyte function in patients with 
low-risk myelodysplastic syndromes [61]. In addition, the species presents an antibacterial, antihypertensive, antihyperglycemic and antihyperlipidemic activity, as described in Su et al. [59].

\subsubsection{Hericium erinaceus}

Hericium erinaceus, an ideal culinary-medicinal mushroom, has become a well-established candidate in promoting positive brain and nerve health-related activities, by inducing the nerve growth factor by its erinacines. Preclinical studies have shown that there can be improvements in Parkinson's, Alzheimer's disease and depression illness, even in ischemic stroke, if H.erinaceus mycelia, enriched with erinacines, are included in daily meals [62,63]. Different clinical trials were carried out with good results. To this respect, a 30-day short-term administration of erinacine $\mathrm{A}$ and $\mathrm{S}$ was performed to explore the effect of each erinacine type on Alzheimer's disease pathology, including amyloid production and degradation, plaque formation, plaque growth, glial activation and neurogenesis deterioration. Results concluded the beneficial effects of both erinacine A and S in cerebrum of APPswe/PS1dE9 mice [64]. A double-blinded clinical study showed that the oral administration of $H$. erinaceus fruiting body was effective in improving mild cognitive impairment in 50- to 80-year-old Japanese patients [63]. Another clinical trial conducted to investigate the effects on dementia found that after 6 months of taking the mushroom, 6 out of 7 patients showed improvement in their perceptual capacities [62]. Endoplasmic-reticulum stress triggers apoptosis on neural cells, being a major cause of degenerative diseases such as Alzheimer's disease. Three new compounds, 3-hydroxyhericenone F, hericenone I, and hericenone J were isolated from $\mathrm{H}$. erinaceus and showed to act as protective against this stress. The principles have been required not only to cure or prevent the diseases but also to investigate the complex system of apoptosis [65]. Considering other nerve-related affections, hericenones showed an antidepressant effect, which may be attributed to the restoration of hippocampal monoamine neurotransmitters, inhibition of plasma pro-inflammatory cytokines and the modulation of PI3K/Akt/GSK-3 $\beta$ pathway with a consequent increase of brain-derived neurotrophic factor (BDNF) expression.

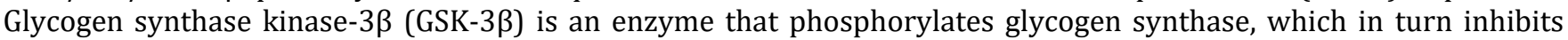
glycogen biosynthesis. Moreover, GSK-3 $\beta$ is now believed to play an important role in the pathophysiology of depression. Literature data indicate that phosphatidylinositol 3-kinase (PI3K) and serine/threonine protein kinase AKT seem to activate immune cells by modulation of the key inflammatory cytokines. In addition, the PI3K/Akt pathway has been reported to play the role as an upstream mechanism of GSK-3 $\beta$ activity regulation, in which Akt might directly phosphorylate GSK-3 $\beta$, resulting in GSK-3 $\beta$ inactivation. Irregularities in the PI3K/Akt/GSK-3 $\beta$ pathway are linked in patients with psychiatric illnesses. Therefore, regulation of AKT and GSK-3 $\beta$ may form an important signaling center for depressive therapy. In Chiu et al. [66], H. erinaceus was demonstrated to be able to increase phosphorylation of Akt and GSK-3 $\beta$. The results so far presented reveal that the antidepressant-like effect of $H$. erinaceus involves the activated pathway of PI3K/Akt and the inhibition of GSK-3 $\beta$ that converge to increase BDNF. Neuroplasticity turns out to be the therapeutic target of antidepressant agents. Thus, BDNF is a member of the neurotrophic factor known to participate in the life of neurons during development and to modulate hippocampal-dependent learning and memory. Accumulating evidence supports that BDNF is indispensable for exerting antidepressant effects because it can modulate synaptic efficacy by changing transmitter release and sensitivity. There is also evidence that the lack of BDNF is linked to the pathophysiology of mood disorders. All of these pathways are key mechanisms in depression treatment, indicating that $H$. erinaceus may represent a potent alternative therapy for depression, ameliorating altered behaviour and neurochemical parameters through several signal transductions, and that these signals may be synchronized with each other [66].

Furthermore, regarding the digestive system, the crude ethanol extracts from $H$. erinaceus were inhibitory to Helicobacter pylori. The study revealed that compounds 1 y 2, from petroleum ether extracts of the species (PE1s and PE2s), contributed to the anti-H.pylori activity. Finally, Hericium erinaceus has been documented to display a wider range of beneficial properties including antimicrobial, antihyperglycemic, hypolipidemic and hemagglutinating activity [66].

\subsubsection{Hypsizygus marmoreus}

Concerning the lipid constituents of H. marmoreus, the sterols might be of importance as treatment for antituberculosis and for cancer chemoprevention, whereas the hypsiziprenols proved to be less effective [67]. Considering its antiproliferative activities, research with fractions of $\mathrm{H}$. marmoreus examined the HepG2 cells in vitro. The results suggested that hypsiziprenol A9 can inhibit the growth of HepG2 cells through inducing G1 phase cell cycle arrest due to the inhibition of some routes of phosphorylation [68].

\subsubsection{Lentinula edodes}

Apart from lentinan, another secondary metabolite was isolated from L. edodes and designated as eritadenine. The agent was responsible for the plasma colesterol-reducing effect in both humans and animals [69]. Enman et al. [70], in the 
search for a production method for eritadenine, investigated shiitake mycelia. The mycelia were cultivated both in shake flasks and in bioreactors, to investigate the effects of $\mathrm{pH}$, stirring rate, and reactor type on the production and distribution of eritadenine. Applying a stirring rate during bioreactor cultivation resulted in the highest eritadenine concentrations. This study demonstrated, for the first time, the extra- and intracellular distribution of eritadenine produced by shiitake mycelial culture and the influence of reactor conditions on the mycelial morphology and eritadenine concentrations [70]. Extracts from L. edodes have more recently revealed, aditionally, antibacterial and antifungal activities [26].

\subsubsection{Morchella esculenta}

Apart from the antioxidant, anti-inflammatory and antitumor activities presented above for this fungi, Nitha et al. [71] indicated that the aqueous-ethanolic extract of M. esculenta mycelium possessed a significant hepatoprotective activity and Cai et al. [72] described its antioxidant properties. The conclusions were supported by biochemical determinations, histopathological and in vitro and in vivo observations.

\subsubsection{Pleurotus ostreatus}

A pronounced hypocholesteremic effect of the oyster mushroom P. ostreatus, combined with the inhibition of lipid peroxidation, was shown in rats and rabbits. An oyster mushroom diet (10\% dried powder from fruiting bodies) significantly reduced the incidence and size of atherosclerotic plaques in rabbits [73]. Furthermore, lovastatin, the lead compound for the statines (HMGCoA reductase inhibitors), was detected in this species and was proved to be jointly responsible for the observed effects [1].

The regular application of the polysaccharide beta-glucan as a based cream showed to be able to decrease the duration and intensity of atopic dermatitis flares, as well as to attenuate the pruritus intensity within a few days of its application. Therefore, it seems to possess anti-infective properties. Additionally, a regular topical administration of the cream demonstrated an increase in skin firmness and stratum corneum hydration, improving skin barrier functions [74].

\subsubsection{Poria cocos}

The species P. cocos is known to have beneficial effects in different treatments like insomnia, water retention and diarrhea. In addition, two sterols, ergosterol peroxide (EP) and 9, 11-dehydroergosterol peroxide were effective in the inhibition of osteoporosis in the elderly [50,51]. Qian et al. [19] indicated that the poricoic acid B, poricoic acid A, pachymic acid, dehydrotrametenolic acid, dehydrotumulosic acid, polyporenic acid $\mathrm{C}$ and dehydropacymic acid were some of the major bioactive compounds of P. cocos contributing to an important diuretic effect. Finally, $P$. cocos also plays a hepatoprotective role against acetaminophen [N-acetyl-p-aminophenol (APAP)], also termed paracetamol, on lesioned liver cells in vivo and in vitro [75].

\subsubsection{Trametes versicolor}

The cytotoxic activity of PSP and PSK extracts from T. versicolor has been reported in myeloid and lymphoid leukemia cell lines [76]. Additionally, the bioactive compound PSP was shown to be successful acting as a prebiotic to modulate human intestinal microbiome composition [77].

\subsection{Adverse effects and/or toxicity and clinical trials}

Some tests have been used for the study of adverse effects and/or toxicity when bioactive compounds, dried, or cooked mushrooms were administered as herbal medicines. In the consulted literature, skin, serological and stool tests have been applied. A range of commercial aeroallergens and food extracts are commonly used to perform skin prick-to-prick tests, scratch tests, atopy and mold screening tests [78]. Some synthetic antioxidants, like beta-glucans (1020 stretching vibration of $\mathrm{C}-0$ ), may cause adverse toxic effects under certain conditions [79]. However, cytotoxic effects of polysaccharide extracts of higher fungi on primary cells have not been reported up-to-date [79, 80]. Thus, the systematic study on the clinical and physiological significance of beta-glucans is scarce [81].

In the present review, we found six species, out of the ten studied, that have reported toxicity or adverse effects after administration. One of the objectives of this revision was to compile the cases that have been published.

\subsubsection{Boletus edulis}

An ingestive allergy of Boletus edulis was in this way diagnosed using the dried mushroom [82]. Allergen-specific IgE antibodies for B. edulis and total IgE in serum were measured with a fluor enzyme immunoassay. The solid-phase allergens were coupled to disks and tested by radio allergo sorbent test (RAST). Thus, the IgG antibody precipitant 
against various mushroom components was demonstrated by immunoelectrophoresis [82]. Two cases after inhalation/ingestion of the mushroom and two cases of anaphylactic reaction after its consumption were identified during a 20-year period at the University Hospital in Zürich [82]. The clinical manifestation in the cases differed from oral allergy syndrome, presenting oropharyngeal itching, tingling, and swelling of the lips, to asthma and anaphylactic episodes, with severe diarrhea, generalized urticaria, asthma attacks with dizziness, hypotension and tachycardia, leading to hospitalization. Further data indicate that B. edulis can cause an IgE-mediated food allergy due to a digestionstabil protein [83]. Adverse reactions after its ingestion were believed to be due to a deficiency trehalase. Another case of occupational allergy was reported in Roncarolo et al. [84] with similar effects. Indole constituents were isolated from B. edulis and some of these constituents were found to be tissue hormones and neuro-transmitters which, together with high intakes of tryptophan, can damage the nervous system [85].

\subsubsection{Ganoderma lucidum}

A hepatotoxic effect related to G. lucidum mushroom powder (known as lingzhi) was shown in two patients in two different episodes [86]. The authors described fatal fulminant hepatitis associated with such a preparation. Firstly, patients used to take boiled lingzhi, in combination with other therapeutic agents, and experienced no toxic/adverse effects, however, after switching to lingzhi ingested as a powder form, for a period of 1-2 months, the hepatotoxic episodes occurred. Thus, the toxic role of lingzhi powder would further need a close monitoring, especially in treatments under the combination with other drugs [86].

Differentiation of parasites from artifacts depended on characterization of the size, shape, structure, and reactivity with common strains. The stool examination in a pseudoparasitosis report in Thailand demonstrated indeed the ingestion of many spores of Ganoderma lucidum in a patient with a history of consumption of powdered extract as a dietary supplement in pharmaceutical medicine [87].

\subsubsection{Grifola frondosa}

Based on epidemiological studies, fungi have been suggested to be responsible for many of the irritative symptoms by inhalation. The total IgE serum levels were determined with an enzyme-linked immunosorbent assay (ELISA). Further western blot analyses of the patients and the control's serum to Grifola frondosa spore antigen showed positive bands [88]. The single inhalation of beta-glucan (grifolan) from $G$. frondosa aerosol was proved to provoke a sensory irritation response in mice [88]. There are several recent reports on hypersensitivity pneumonitis (HP) warning about mushroom farms which may carry a significant risk. Thus, occupational HP, caused by G. frondosa spores, has been described, particularly the treatment, using a HFA-BDP extra-fine aerosol, resulted successful [89]. One case of acute encephalopathy, diagnosed at hospital, was apparently due to $G$. frondosa. Fourteen days after the ingestion, the patient developed cramps, lost consciousness and fell into a coma. The authors suggested that hydrogen cyanide from the mushroom could have been the causative fatal agent [90].

\subsubsection{Lentinula edodes}

The ingestion of the L. edodes mushroom was shown to produce eosinophilia and gastrointestinal symptoms. In clinical trials, the subjects were monitored for the development of symptoms, and complete blood counts and serum samples were obtained, biweekly or weekly. Additionally, the serum major basic protein (MBP) levels were determined by an immunoradiometric assay [91].

A cholesterol-lowering study with L. edodes (shiitake powder) showed that 17 out of 49 participants withdrew the trial because of rash or abdominal discomfort, and two had marked eosinophilia. One of these latter participants was subsequently challenged for 14 days with shiitake powder and again had eosinophilia. Daily ingestion of shiitake mushroom powder in five of 10 healthy persons provoked blood eosinophilia, increased eosinophil granule proteins in serum and stool, and increased gastrointestinal symptoms. Seventeen days after the last shiitake ingestion, eosinophilrelated parameters were decreasing to or at normal levels [91].

Other immunological reactions associated with the shiitake mushroom have been described. These reactions have included contact dermatitis, generalized pruritus, and HP. However, the response is likely immune-mediated because it is associated with cytokines that enhance eosinophil viability and elevations in antishiitake IgG [91]. In addition, Lentinula edodes has dissolved compounds of purines, where sensible patients with gout, for example, should avoid or severely limit the intake of this species. Dissolution rates of polysaccharide and purine compounds from $L$. edodes increased linearly when increasing the duration of cooking or when adding acetic acid, or NaHCO3, in the soaking or cooking solutions [92]. 
Several intoxications have been reported after consumption of $L$. edodes, apparently in almost all cases after consumption of insufficiently processed mushrooms. The toxicant is supposed to be the thermolabile polysaccharide lentinan (one of its major bioactive compounds). Shiitake- flagellate dermatitis, also known as flagellate erythema or toxicoderma, was correlated with the ingestion of underprocessed shiitake. A linear, erythematous eruption appears resembling scratch or whiplash marks. There are several cases described to this respect [93-95], as well as to dermatosis in a Caucasian person [96], and dermatitis caused by shiitake [97]. Another type of hypersensitivity effect to shiitake was described by Goikoetxea et al. [98] in a patient that showed oesophageal symptoms after ingestion. The allergenicity was confirmed by skin prick, basophile activation and histamine release tests.

\subsubsection{Morchella esculenta}

Morels should only be eaten after parboiling and removal of the boiling water and/or after a correct dehydration process [99]. Intoxications with gastrointestinal symptoms have been reported occasionally, as well as the cerebellar syndrome, the latter if consumed in large amounts [100,101]. In addition, a mild hemolytic syndrome was rarely manifested by a darker colour of the urine, and in more severe cases, with symptoms like vomiting, diarrhea, hemoglobinuria, anemia, low back pain and kidney failure [99,102,103]. However, in relation to the bioactive compound extracts from Morchella sp., it seems that FMP-1 has no significant toxic effect on the cells under study [104].

\subsubsection{Pleurotus ostreatus}

There are some indications referring that the oyster mushroom may give adverse effects [105-107]. Berne et al. [107] isolated and characterized a thermolabile protein, ostreolysin. It is a cytolysin which lyses bovine, sheep and human erythrocytes in vitro and probably also has similar effects in vivo, as indicated by increased serum potassium [108]. After parenteral application of ostreolysin to rats, an endothelial injury with edema in the heart and lungs, as well as myocardial hemorrhages, could be demonstrated [106]. In 2004, Tomita et al. [109] isolated and characterized a two component, pore-forming cytolysin, pleurotolysin, which consists of two, non-associated components, pleurolysin A (molecular weight $17 \mathrm{kDa}$ ) and pleurolysin B (molecular weight $52 \mathrm{kDa}$ ). Cooperatively, these two components caused leakage of potassium ions from human erythrocytes and swelling, leading to hemolysis [109,110]. Considering its bioactive compounds, no adverse effects were found in synthetic ergothioneine [111]. Studies in animals and humans have found no toxicity or adverse effects associated with the administration of ergothioneine, even at very high doses [112].

\section{Conclusion}

The present study is an updated review on the potential of ten of the most known mushrooms used as a source of drugs for herbal medicine due to their wide variety of bioactive components. The majority of the references here consulted were therefore from studies carried out in China or Japan, whereas in Europe and America the awareness of mushrooms, as an important source of biologically active substances, has recently emerged. The present review pointed out, for the first time, adverse effects in individual daily consumption and during clinical trials. Beta-glucans had caused toxic effects under certain conditions and their cytotoxic effect on primary cells still would need further research. B. edulis caused an IgE-mediated food allergy due to a digestion-stabil protein; G. lucidum mushroom powder showed a slight hepatotoxic effect; hypersensitivity pneumonitis was caused by G. frondosa spores in some patients, as well as L. edodes powder had caused rash, eosinophilia and abdominal discomfort. In contrast, no toxic or adverse effects were found in synthetic ergothioneine from Pleurotus or in FMP-1 from Morchella. Further research will help identifying the mechanism of action of some active ingredients on newly discovered effects. Further toxicity studies performing in vitro and in vivo models should reach more conclusions to hold the promise of providing new natural substances for the pharmaceutical medicine.

\section{Abbreviations}

DLPE: dilinoleoyl-phosphatidylethanolamine; MSPS: mycelia selenium polysaccharides; FMP1: polysaccharide from Morchella; PSK: polysaccharopeptide Krestin; PSP: polysaccharopeptide

\section{Compliance with ethical standards}

\section{Acknowledgments}

We thank an anonymous referee for the final editing of the manuscript. 


\section{Disclosure of conflict of interest}

The authors have no conflict of interest to disclose.

\section{Funding}

This research did not receive any specific grant from the public, comercial or not-for-profit sectors.

\section{References}

[1] Lindequist U, Niedermeyer THJ, Jülich WD. The pharmacological potential of mushrooms. Complementary and Alternative Medicine. 2005; 2:285-299.

[2] Chaturvedi VK, Agarwal S, Gupta KK, Ramteke PW, Singh MP. Medicinal mushroom: boon for therapeutic applications. Biotechnology. 2018; 8(8):334.

[3] Geng P, Siu KC, Wang Z, Wu JY. Antifatigue Functions and Mechanisms of Edible and Medicinal Mushrooms. BioMedical Research. International. 2017; 1-16.

[4] Takur MP, Singh HK.Medicinal Plants. International Journal of Phytomedicine. Rel. Industries. 2013; 5(1): 1.

[5] Rossi P, Difrancia R, Quagliariello V, Savino E, Tralongo P, Randazzo CL, Berretta M, B-glucans from Grifola frondosa and Ganoderma lucidum in breast cancer: an example of complementary and integrative medicine. Oncotarget. 2018; 9(37):24837-24856.

[6] Gao Y, Zhou S, Chen, G, Dai X, Ye J. A phase I/II study of a Ganoderma lucidum (Curt:Fr.) P.Karst.extract (Ganopoly) in patients with advanced cancer. International Journal of Medicinal Mushrooms. 2002; 4:207-14.

[7] Gao Y, Dai X, Chen G, Ye J, Zhou S. A randomized, placebo-controlled, multicenter study of Ganoderma lucidum (W.Curt.Fr.) Lloyd (Aphylloromycetidae) polysaccharides (Ganopoly R) in patients with advanced lung cancer. International Journal of Medicinal Mushrooms. 2003; 5:369-381.

[8] Gordon M, Guralnik M, Kaneko Y, Mimura T, Goodgame J, DeMarzo C, Pierce D, Bake, M, Lang W. A phase II controlled study of a combination of the immune modulator, lentinan, with didanosine (ddI) in HIV patients with CD4 cells of 200-500/mm3. Journal of Medicine. 1995; 26(5-6):193-207.

[9] Ina K, Furuta R, Kataoka T, Kayukawa S, Ina H, Yoneda M. Chemo-Immunotherapy Using Lentinan for the Treatment of Gastric Cancer with Liver Metastases. Medical Science. 2016; 4(2):8.

[10] Zhang Y, Zhang M, Jiang Y, Li X, He Y, Zeng P, Guo Z, Chang Y, Luo H, Liu Y, Hao C, Wang H, Zhang G, Zhang L. Lentinan as an immunotherapeutic for treating lung cancer: a review of 12 years of clinical studies in China. Journal of Cancer Research and Clinical Oncology. 2018; 144(11): 2177-2186.

[11] Kosanić M, Ranković B, Dašić M. Mushrooms as Possible Antioxidant and Antimicrobial Agents Iran. Journal of Pharmacological Research. 2012; 11(4):1095-1102.

[12] Brandt CR, Piraino F.Mushrooms antivirals. Recent. Res. Dev. Antimicrobial Agents and Chemotherapy. 2000; 4:11-26.

[13] Dubost NJ, Beelman R,Peterson DG, Royse DJ. Identification and Quantification of Ergothioneine in Cultivated Mushrooms by Liquid Chromatography-Mass Spectroscopy. International Journal of Medicinal Mushrooms. 2006; 8(3):215-222.

[14] Feng T, Zheng-Hui L, Dong Z-J, Li Y, Liu JK. Non-isoprenoid botryane sesquiterpenoids from basiodiomycete Boletus edulis and their cytotoxic activity. Natural Products and Bioprospecting. 2011; 1:29-32.

[15] Bovi M, Carrizo ME, Capaldi S, Massimilano P, Chiarelli LR, Galliano M, Monaco HL. Structure of a lectin with antitumoral properties in king bolete (Boletus edulis) mushroom. Glycobiology 2011; 21:1000-1009.

[16] Ren Z, Liu W, Song X, Qi Y, Zhang C, Gao Z, Zhang J, Jia L. Antioxidant and anti-inflammation of enzymatichydrolysis residue polysaccharides by Lentinula edodes. International Journal of Biological Macromolecules. 2018; 120:811-822.

[17] Ren G, Xu L, Lu T, Yin J. Structural characterization and antiviral activity of lentinan from Lentinus edodes mycelia against infectious hematopoietic necrosis virus. International Journal of Biological Macromolecules. 2018; 115:1202-1210. 
[18] Liu C, Sun Y, Mao Q, Guo X, Li P, Liu Y, Xu N. Characteristics and Antitumor Activity of Morchella esculenta Polysaccharide Extracted by Pulsed Electric Field. International Journal of Molecular Science. 2016; $17(6): 986$.

[19] Qian Q, Zhou N, Qi P, Zhang Y, Mu X, Shi X, Wang Q. A UHPLC-QTOF-MS/MS method for the simultaneous determination of eight triterpene compounds from Poria cocos (Schw. Wolf) extract in rat plasma: Application to a comparative pharmacokinetic study. Journal of Chromatography B: Analytical Technologies in the Biomedical and Life Sciences. 2018; 1102:34-44.

[20] Scarpari M, Reverberi M, Parroni A, Scala V, Fanelli C, Pietricola C, Zjalic S. et al. Tramesan, a novel polysaccharide from Trametes versicolor. Structural characterization and biological effects. PLoS One 2017; 12(8).

[21] Tsai SH, Tsai HL, Mau JL. Antioxidant properties of Agaricus blazei, Agrocybe cylindracea, and Boletus edulis. LWT. 2007; 40:1392-1402.

[22] Jaworska G, Pogoń K, Skrzypczak A, Bernaś E. Composition and antioxidant properties of wild mushrooms Boletus edulis and Xerocomus badius prepared for consumption. Journal of Food Science and Technology. 2015; 52(12):7944-7953.

[23] Lo YC, Lin SY, Ulziijargal E, Chen SY, Chien RC, Tzou YJ, Mau JL. Comparative study of contents of several bioactive components in fruiting bodies and mycelia of culinary-medicinal mushrooms. International Journal of Medicinal Mushrooms. 2012; 14(4):357-363.

[24] Wang J, Cao B, Zhao H, Feng J. Emerging Roles of Ganoderma Lucidum in Anti-Aging. Aging and Disease. 2017; 8(6):691-707.

[25] Lin ZB. Focus on antioxidative and free radical scavenging activity of Ganoderma lucidum. Journal of Applied Pharmacology. 2004; 12:133-137.

[26] Chowdhury M, Kubra K, Ahmed S. Screening of antimicrobial, antioxidant properties and bioactive compounds of some edible mushrooms cultivated in Bangladesh. Annals of Clinical Microbiology and Antimicrobials. 2015; 14:8.

[27] Vamanu E. In vitro antimicrobial and antioxidant activities of ethanolic extract of lyophilized mycelium of Pleurotus ostreatus PQMZ91109. Molecules. 2012; 17(4):3653-3671.

[28] Bobek P, Galbavy S. Effect of pleuran (beta-glucan from Pleurotus ostreatus) on the antioxidant status of the organism and on dimethylhydrazine-induced precancerous lesions in rat colon. Br. Journal of Biomedical Science. 2001; 58(3):164-168.

[29] Li W, Cai ZN, Mehmood S, Wang Y, Pan WJ, Zhang WN, Lu YM, Chen Y. Polysaccharide FMP-1 from Morchella esculenta attenuates cellular oxidative damage in human alveolar epithelial A549 cells through PI3K/AKT/Nrf2/HO-1 pathway. International Journal of Biological Macromolecules. 2018; 120 (Pt A):865-875.

[30] Muszyńska B, Grzywacz-Kisielewska A, Kała K, Gdula-Argasińska J. Anti-inflammatory properties of edible mushrooms: A review. Food Chemistry. 2018; 243:373-381.

[31] Lu SY, Peng XR, Dong JR, Yan H, Kong QH, Shi QQ, Li DS, Zhou L, Li ZR, Qiu MH. Aromatic constituents from Ganoderma lucidum and their neuroprotective and anti-inflammatory activities. Fitoterapia. 2019; 134:58-64.

[32] Wu YL, Han F, Luan SS, Ai R, Zhang P, Li H, Chen LX. Triterpenoids from Ganoderma lucidum and Their Potential Anti-inflammatory Effects. Journal of Agriculture and Food Chemistry. 2019; 8, 67(18):5147-5158.

[33] Zhang Y, Mills G, Nair MG. Cyclooxygenase inhibitory and antioxidant compounds from the mycelia of the edible mushroom Grifola frondosa. Journal of Agriculture and Food Chemistry. 2002; 50:7581-7855.

[34] Liu M, Yao W, Zhu Y, Liu H, Zhang J, Jia L. Characterization, antioxidant and antiinflammation of mycelia selenium polysaccharides from Hypsizygus marmoreus SK-03. Carbohydrate Polymers. 2018; 201:566-574.

[35] Li W, Cai ZN, Mehmood S, Liang LL, Liu Y, Zhang HY, Chen Y, Lu YM. Anti-inflammatory effects of Morchella esculenta polysaccharide and its derivatives in fine particulate matter-treated NR8383 cells. International Journal of Biological Macromolecules. 2019; 129:904-915.

[36] Cai TG, Cai Y. Triterpenes from the fungus Poria cocos and their inhibitory activity on nitric oxide production in mouse macrophages via blockade of activating Protein-1 pathway. Chemical Biodiversity. 2011; 8:2135-2143.

[37] El-Mekkawy S, Meselhy MR, Nakamura N, Tezuka Y, Hattori M, Kakiuchi N, Shimotohno K, Kawahata T, Otake T. Anti-HIV-1 and HIV-1-protease substances from Ganoderma lucidum. Phytochemistry. 1998; 49 (6):1651-1657. 
[38] Wu QP, Xie YZ, Deng Z, Li XM, Yang W, Jiao CW, Fang L, Li SZ et al. Ergosterol Peroxide Isolated from Ganoderma lucidum Abolishes MicroRNA miR-378-Mediated Tumor Cells on Chemoresistance. PLoS One 2012; 7(8).

[39] Nanba H, Kodama N, Schar D, Turner D. Effects of maitake (Grifola frondosa) glucan in HIV-infected patients. Mycoscience. 2000; 41:293-295.

[40] Zhao C, Gao L, Wang C, Liu B, Jin Y, Xing Z. Structural characterization and antiviral activity of a novel heteropolysaccharide isolated from Grifola frondosa against enterovirus 71. Carbohydrate Polymers. 2016; 144:382-389.

[41] Lam SK, Ng TB. Hypsin, a novel thermostable ribosome-inactivating protein with antifungal and antiproliferative activities from fruiting bodies of the edible mushroom Hypsizigus marmoreus. Bioch. Biophys. Res. Comm. 2001; 285:1071-1075.

[42] Suzuki H, Okubo A, Yamazaki S, Suzuki K, Mitsuya H.S. Inhibition of the infectivity and cytopathic effect of human immunodeficiency virus by watersoluble lignin in an extract of the culture medium of Lentinus edodes mycelia (LEM), Biochemical and Biophysical Research Communications. 1989; 160:367-373.

[43] Sarkar S, Koga J, Whitley RJ, Chatterjee S. Antiviral effect of the extract of culture medium of Lentinus edodes mycelia on the replication of herpes simplex virus type 1. Antiviral Research. 1993; 20:293-303.

[44] Tochikura TS, Nakashima H, Hirose K, Yamamoto N. A biological response modifier, PSK, inhibits human immunodeficiency virus infection in vitro. Biochemical and Biophysical Research Communications. 1987; 148:726-733.

[45] Alonso EN, Ferronato MJ, Gandini NA, Fermento ME, Obiol DJ, López Romero A, Arévalo J, Villegas ME, Facchinetti MM, Curino AC. Antitumoral Effects of D-Fraction from Grifola Frondosa (Maitake) Mushroom in Breast Cancer. Nutrition and Cancer. 2017; 69(1):29-43.

[46] Cör D, Knez Ž, Knez Hrnčič M. Antitumour, antimicrobial, antioxidant and antiacetylcholinesterase effect of Ganoderma lucidum terpenoids and polysaccharides: A Review. Molecules. 2018; 23(3):649.

[47] Gao Y, Gao H, Chan E, Tang W, Xu A, Yang H, Huang M, Lan J, Li X, Duan W, Xu C, Zhou S. Antitumor activity and underlying mechanisms of ganopoly, the refined polysaccharides extracted from Ganoderma lucidum in mice. Immunological Investigations. 2005; 34(2):171-98.

[48] Kim JW, Kim HI, Kim JH, Kwon OC, Son ES, Lee CS, Park YJ. Effects of Ganodermanondiol, a New Melanogenesis Inhibitor from the Medicinal Mushroom Ganoderma lucidum. International Journal of Molecular Science. 2016; 17(11):1798.

[49] Konno S, Aynehchi S, Dolin DJ, Schwarz AM, Choudhury MS, Tazaki H. Anticancer and hypoglycemic polusaccharides in edible and medicinal mushroom [Grifola frondosa (Dicks.:Fr.) S.F. Gray] International Journal of Medicinal Mushrooms. 2002; 4:185-195.

[50] Lee S, Choi E, Yang SM, Ryoo R, Moon E, Kim SH, Kim KH. Bioactive compounds from sclerotia extract of Poria cocos that control adipocyte and osteoblast differentiation. Bioorganic Chemistry. 2018; 81:27-34.

[51] Lee S, Lee S, Roh HS, Song SS, Ryoo R, Pang C, Baek KH, Kim KH. Cytotoxic Constituents from the Sclerotia of Poria cocos against Human Lung Adenocarcinoma Cells by Inducing Mitochondrial Apoptosis. Cells. 2018; 7(9):E116.

[52] Kodama N, Komuta K, Nanba H. Can maitake MD-fraction aid cancer patients? Alternative Medicine Review. 2002; 7(3):236-239.

[53] Baker M, Lang W. A phase II-controlled study of a combination of the immune modulator, lentinan, with didanosine (ddI) in HIV patients with CD4 cells of 200-500/mm3. Journal of Medicine. 1995; 26(5-6):193-207.

[54] Soares R, Meireles M, Rocha A, Pirraco A, Obiol D, Alonso E, Joos G, Balogh G. Maitake (D fraction) mushroom extract induces apoptosis in breast cancer cells by BAK-1 gene activation. Journal of Medicinal Food. 2011; 14(6):563-572.

[55] Mitomi T, Tsuchiya S, Iijima N, Aso K, Suzuki K, Nishiyama K, et al. Randomized controlled study on adjuvant immunochemotherapy with PSK in curatively resected colorectal cancer. Diseases of the Colon and Rectum. 1992; 35:123-130.

[56] Yang QY. A new biological response modifier PSP. In: Chang ST eds. Mushroom Biology and Mushroom Products. Hong Kong: The Chinese University Press; 1993; p. 247-59. 
[57] Nosál'ová V, Bobek P, Cerná S, Galbavý S, Stvrtina S. Effects of pleuran (beta-glucan isolated from Pleurotus ostreatus) on experimental colitis in rats. Physiological Research. 2001; 50(6):575-581.

[58] Jesenak M, Hrubisko M, Majtan J, Rennerova Z, Banovcin P. Anti-allergic effect of Pleuran ( $\beta$-glucan from Pleurotus ostreatus) in children with recurrent respiratory tract infections. Phytotherapy Research. 2014; 28:471-474.

[59] Su CH, Lu TM, Lai MN, Ng LT. Inhibitory potential of Grifola frondosa bioactive fractions on $\alpha$-amylase and $\alpha$ glucosidase for management of hyperglycemia. Biotechnology and Applied Biochemistry. 2013; 60(4):446-452.

[60] Ma X, Zhou F, Chen Y, Zhang Y, Hou L, Cao X, Wang C. A polysaccharide from Grifola frondosa relieves insulin resistance of HepG2 cell by Akt-GSK-3 pathway. Glycoconjugate Journal. 2014; 31(5):355-363.

[61] Wesa KM, Cunningham-Rundles S, Klimek VM, Vertosick E, Coleton MI, Yeung KS, Lin H, Nimer S, Cassileth BR. Maitake mushroom extract in myelodysplastic syndromes (MDS): a phase II study. Cancer Immunology and Immunotherapy. 2015; 64(2):237-247.

[62] Kawagishi H, Zhuang C. Compounds for dementia from Hericium erinaceum. Drugs of the Future. 2008; 33(2):149-155.

[63] Li IC, Lee LY, Tzeng TT, Chen WP, Chen YP, Shiao YJ, Chen CC. Neurohealth Properties of Hericium erinaceus mycelia enriched with erinacines. Behaviour and Neurology. 2018; ID 580263.

[64] Tzeng TT, Chen CC, Chen CC, Tsay HJ, Lee LY, Chen WP, Shen CC, Shiao YJ. The Cyanthin Diterpenoid and Sesterterpene Constituents of Hericium erinaceus Mycelium Ameliorate Alzheimer's Disease-Related Pathologies in APP/PS1 Transgenic Mice. International Journal of Molecular Science. 2018; 19(2):E598.

[65] Ueda K, Tsujimori M, Kodani S, Chiba A, Masakazu K, Kazuhiko M, Atsushi S, Kaoru N, Hirokazu K. An endoplasmic reticulum (ER) stress-suppressive compound and its analogues from the mushroom Hericium erinaceum. Bioorganic Medicinal Chemistry. 2018; 16:9467-9470.

[66] Chiu CH, Chyau CC, Chen CC, Lee LY, Chen WP, Liu JL, Lin WH, Mong MC. Erinacine A-Enriched Hericium erinaceus Mycelium Produces Antidepressant-Like Effects through Modulating BDNF/PI3K/Akt/GSK-3 $\beta$ Signaling in Mice. International Journal of Molecular Science. 2018; 19(2): E341.

[67] Akihisa T, Franzblau SG, Tokuda H, Tagata M, Ukiya M, Matsuzawa T, Metori K, Kimura Y, Suzuki T, Yasukawa K. Antitubercular activity and inhibitory effect on Epstein-Barr virus activation of sterols and polyisoprenepolyols from an edible mushroom Hypsizigus marmoreus. Biological and Pharmaceutical Bulletin. 2005; 28:1117-1119.

[68] Chang JS, Son JK, Li G, Oh EJ, Kim JY, Park SH, Bae JT, Kim HJ, Lee IS, Kim OM, Kozukue N, Han JS, Hirose M, Lee KR. Inhibition of cell cycle progression on HepG2 cells by hypsiziprenol A9, isolated from Hypsizigus marmoreus. Cancer Letters. 2004; 212(1):7-14.

[69] Suzuki S, Ohshima S. Influence of shiitake (Lentinus edodes) on human serum cholesterol. Proceedings of the 9th International Scientific Congress on the Cultivation of Edible Fungi, Tokyo. 1974; 9:463-467.

[70] Enman J, Hodge D, Berglund KA, Rova U. Production of the bioactive compound eritadenine by submerged cultivation of shiitake (Lentinus edodes) mycelia. Journal of Agriculture and Food Chemistry. 2008; 56(8):26092612.

[71] Nitha B, Fijesh PV, Janardhanan KK. Hepatoprotective activity of cultured mycelium of Morel mushroom, Morchella esculenta. Experimental Toxicology and Pathology. 2013; 65(1-2):105-112.

[72] Cai ZN, Li W, Mehmood S, Pan WJ, Wang Y, Meng FJ, Wang XF, Lu YM, Chen Y. Structural characterization, in vitro and in vivo antioxidant activities of a heteropolysaccharide from the fruiting bodies of Morchella esculenta. Carbohydrate Polymers. 2018; 195:29-38.

[73] Bobek P, Galbavy S. Hypocholesteremic and antiatherogenic effect of oyster mushroom (Pleurotus ostreatus) in rabbits. The Journal Nahrung. 1999; 4:339-342.

[74] Jesenak M, Urbancek S, Majtan J, Banovcin P, Hercogova J. $\beta$-Glucan-based cream (containing pleuran isolated from Pleurotus ostreatus) in supportive treatment of mild-to-moderate atopic dermatitis. Journal of Dermatological Treatment. 2016; 27(4):351-354.

[75] Wu K, Guo C, Yang B, Wu X, Wang W. Antihepatotoxic benefits of Poria cocos polysaccharides on acetaminophenlesioned livers in vivo and in vitro. Journal of Cell Biochemistry. 2019; 120(5):7482-7488. 
[76] Ricciardi MR, Licchetta R, Mirabilii S, Scarpari M, Parroni A, Fabbri AA, Cescutti P. et al. Preclinical Antileukemia Activity of Tramesan: A Newly Identified Bioactive Fungal Metabolite. Oxidative Medicine and Cellular Longevity. 2017; Article ID 5061639.

[77] Pallav K, Dowd SE, Villafuerte J, Yang X, Kabbani T, Hansen J. et al. Effects of polysaccharopeptide from Trametes versicolor and amoxicillin on the gut microbiome of healthy volunteers, Gut. Microbes Journal. 2014; 5(4):458467.

[78] Dreborg S. Skin tests used in type I allergy testing. Position paper. Allergy. 1989; 44 (10): 1-59.

[79] Kozarski M, Klaus A, Niksic M, van Griensven L, Vrivic M, Jakovijevic D. Polysaccharides of higher fungi: biological role, structure and antioxidative activity. Hem. Ind. 2014; 68(3):305-320.

[80] Kozarski M, Klaus A, Jakorvijevic D, Todorovic N, Vunduk J, Petrovic P. et al., Antioxidants of edible mushrooms. Molecules. 2015; 20:19489-19525.

[81] Bashir K, Choi J-S. Clinical and physiological perspectives of beta-blucans: The past, present and future. International Journal of Molecular Science. 2017; 18:1906.

[82] Torricelli R, Johansson SG, Wüthrich B. Ingestive and inhalative allergy to the mushroom Boletus edulis. Allergy 1997; 52:747-751.

[83] Helbling A, Bonadies N, Brander KA Pichler WJ. Boletus edulis: A digestion resistant allergen may be relevant for food allergy. Clinical and Experimental Allergy. 2002; 32:771-775.

[84] Roncarolo D, Minale P, Mistrello G, Voltolini S, Falagiani P. Food allergy to Boletus edulis. Journal of Allergy and Clinical Immunology. 1998; 101:850-851.

[85] Stone TW, Mackay GM, Forrest CM, Clark CJ, Darlington LG. Tryptophan metabolites and brain disorders. Clinical and Chemical Laboratory Medicine. 2003; 41:852-859.

[86] Wanmuang H, Leopairut J, Kositchaiwat C. et al. Fatal fulminant hepatitis associated with Ganoderma lucidum (Lingzhi) mushroom powder. Journal of Medical Association of Thailand. 2007; 90(1):179-181.

[87] Wanachiwanawin D, Piankijagum A, Chaiprasert A. et al. Ganoderma lucidum: a cause of pseudoparasitosis. Southeast Asian Journal of Tropical Medicine and Public Health. 2006; 37(6):1099-1102.

[88] Korpi A, Kasanen JP, Kosma VM, Rylander R, Pasanen AL. Slight respiratory irritation but not inflammation in mice exposed to 1, 3-beta-D-glucan aerosols. Mediators of Inflammation 2003; 12(3):139-146.

[89] Tanaka H, Tsunematsu K, Nakamura N, Suzuki K, Tanaka N, Takeya I, Saikai T, Abe S. Successful treatment of hypersensitivity pneumonitis caused by Grifola frondosa (Maitake) mushroom using a HFA-BDP extra-fine aerosol. Internal Medicine. 2004; 43(8): 737-740.

[90] Gonmori K, Yokoyama K. Acute encephalopathy caused by cyanogenic fungi in 2004, and magic mushroom regulation in Japan. Japanese Journal of Clinincal Toxicology. 2009; 22:61-69.

[91] Levy AM, Kita H, Phillips SF, Schkade PA, Dyer PD, Gleich GJ, Dubravec V.A. Eosinophilia and gastrointestinal symptoms after ingestion of shiitake mushrooms. Journal of Allergy and Clinical Immunology. 1998; 101:613620 .

[92] Zhu, L., Wang, S., Zhang, Z., Zhou, S., Tang, Q., Wu, F., Zhang, JS.Dissolution of Bioactive Components from Dried Fruiting Bodies of the Culinary- Medicinal Shiitake Mushroom, Lentinus edodes (Agaricomycetes), during Cleaning, Soaking, and Cooking. International Journal of Medicinal Mushrooms 2019; 21(1): 37-45.

[93] Fang S, Bajoghli A, Bajoghli M. Shiitake mushroom-induced flagellate dermatitis. Annals of Allergy and Asthma Immunology. 2017; 119(5):462-463.

[94] Maher AM, Ward CE, Pratt M. Shiitake dermatitis after consumption of homemade Soup. Dermatitis. 2018; 29(1):43-44.

[95] Nguyen AH, Gonzaga MI, Lim VM, Adler MJ, Mitkov MV, Cappel MA. Clinical features of shiitake dermatitis: a systematic review. International Journal of Dermatology. 2017; 56(6):610-616.

[96] Didona D, Mostaccioli S, Paolino G, Cantisani C, Caposiena Caro RD, Viti G, Didona B. Shiitake dermatosis in a Caucasian woman. G. Ital. Dermatology and Venereology. 2018; 153(4): 586-588.

[97] Forward E, Chee SN, Smith S.D. A case of shiitake mushroom dermatitis. Journal of Medicinal Food. 2018; 21(2):136-145. 
[98] Goikoetxea MJ, Fernández-Benítez M, Sanz ML. Food allergy to Shiitake (Lentinus edodes) manifested as oesophageal symptoms in a patient with probable eosinophilic oesophagitis. Allergy and Immunopathology. 2009; 37:333-334.

[99] Gry J. and Andersson C. Mushrooms traded as food. Vol II (2). Temanord: 507, 309. Nordic Council of Ministers; 2014. p. 471.

[100] Pfab R, Haberl B, Kleber J, Zilker T. Cerebellar effects after consumption of edible morels, Morchella conica and Morchella esculenta. Clinical Toxicology. 2008; 46:249-260.

[101] Saviuc P, Harry P, Pulce C, Garnier R, Cochet A. Can morels (Morchella sp.) induce a toxic neurological síndrome? Clinical Toxicology. 2010; 48:365-372.

[102] Piqueras J. Haemolytic intoxication by mushrooms. In: Plant and Fungi Intoxications. Chapter 31 . Masson Ed. Barcelona; 1996; p111-113.

[103] Piqueras J. The toxicity of morels: Facts, myths and hypothesis. A.M. Font I Quer. 2013; 7:32-47.

[104] Cai ZN, Li W, Mehmood S, Pan WJ, Wu QX, Chen Y, Lu YM. Effect of polysaccharide FMP-1 from Morchella esculenta on melanogenesis in B16F10 cells and zebrafish. Food Function. 2018; 9(9):5007-5015.

[105] Al-Deen IHS, Twaij HAA, Al-Badr AA, Istarabadi TAW. Toxicologic and histopathologic studies of Pleurotus ostreatus in mice. Journal of Ethnopharmacy. 1987; 21:297-305.

[106] Juntes P, Rebolj K, Sepcic K, Macek P, Zuzek MC, Cestnik V, Frangez R. Ostreolysin induces sustained contraction of porcine coronary arteries and endothelial dysfunction in middle- and large-size vessels. Toxicon. 2009; 54:784-792.

[107] Berne S, Krizaj I, Pohleven F, Turk T, Macek P, Sepčic K. Pleurotus and Agrocybe hemolysins, new proteins hypothetically involved in fungal fruiting. Biochem. Biophys. Acta 2002; 1570:153-159.

[108] Zuzek MC, Macek P, Sepcic K, Cestnik V, Frangez R. Toxic and lethal effects of ostreolysin, a cytolytic protein from edible oyster mushroom (Pleurotus ostreatus) in rodents. Toxicon. 2006; 48:264-271.

[109] Tomita T, Noguchi K, Mimuro H, Ukaji F, Ito K, Sugawara-Tomita N, Hashimoto Y. Pleurotolysin, a novel sphingomyelin-specific two-component cytolysin from the edible mushroom Pleurotus ostreatus, assembles into a transmembrane pore complex. Journal of Biochemical Chemistry. 2004; 279:26975-26982.

[110] Sepcic K, Berne S, Potrich C, Turk T, Macek P, Menestrina G. Interaction of ostreolysin, a cytolytic protein from the edible mushroom Pleurotus ostreatus, with lipid membranes and modulation of lysopospholipids. European Journal of Biochemistry. 2003; 270:1199-1210.

[111] EFSA, European Commission following an application of Tetrahedron. Safety of synthethic l-ergothioneine as a novel food pursuant to regulation (EC) No 258/97. EFSA-Q-2015-00613; 2016. doi: 10.2093/j.efsa.2016.4629.

[112] Halliwell B, Cheah I. Ergothioneine: The magic in mushrooms; (c)2009 [cited 2019 Ap 23]. Available from http://news.nus.edu.sg. 